\title{
Intramural duodenal haematoma caused by pancreatic fistula due to exacerbation of chronic pancreatitis
}

\author{
Junya Kitadani, Naohisa Yamade, Hiroaki Nakai, Koichi Shima
}

Department of Surgery, Shingu Municipal Medical Center, Shingu, Japan

\section{Correspondence to} Dr Junya Kitadani,

kitadani@wakayama-med.ac.jp

Accepted 8 February 2018

\section{DESCRIPTION}

Intramural duodenal haematoma (IDH) is a rare condition forming haematoma within the wall of the duodenum, which was first reported in 1838 by MacLauchlan. ${ }^{1}$ IDH derived from acute or chronic pancreatitis is rarely described, the mechanism remaining unknown. A 65 -year-old man with history of heavy drinking and chronic hepatitis was admitted to our hospital with sudden vomiting and right-lateral abdominal pain. Abdominal pain and vomiting continued after admission, so a nasogastric tube was inserted. Contrast-enhanced CT scans of the abdomen found a $60 \times 80 \mathrm{~mm}$ heterogeneous mass with intraluminal leakage of contrast agent-like bleeding along the second portion of the duodenum, diffuse expansion of the pancreatic duct with pancreatic stone and ascites on the surface of the liver (figure 1). We first considered whether the mass might be duodenal gastrointestinal stromal tumour with internal bleeding according to symptoms and enhanced CT image. However, gastrointestinal endoscopy showed mucosal redness and protrusion into the lumen at the second portion of the duodenum, which was flattened when air was delivered. Additionally, endoscopic ultrasound and MRI found that the mass contained only fluid without solid component. We finally diagnosed IDH according to these examinations. IDH often improves with conservative treatment. ${ }^{2}$ The indication for conservative treatment of IDH is to satisfy the following; no other organ damage, no major bleeding, and improvement of obstructive

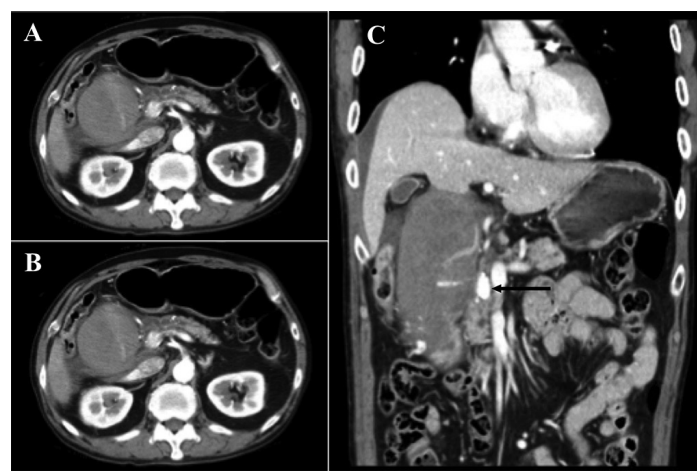

Figure 1 Enhanced CT images of the abdomen show large mass lesion with the intraluminal leakage of contrast agent along the second portion of the duodenum. They also reveal diffuse expansion of pancreatic duct, huge pancreatic stone (black arrow) and ascites on the surface of the liver $(\mathbf{A}-\mathbf{C})$.

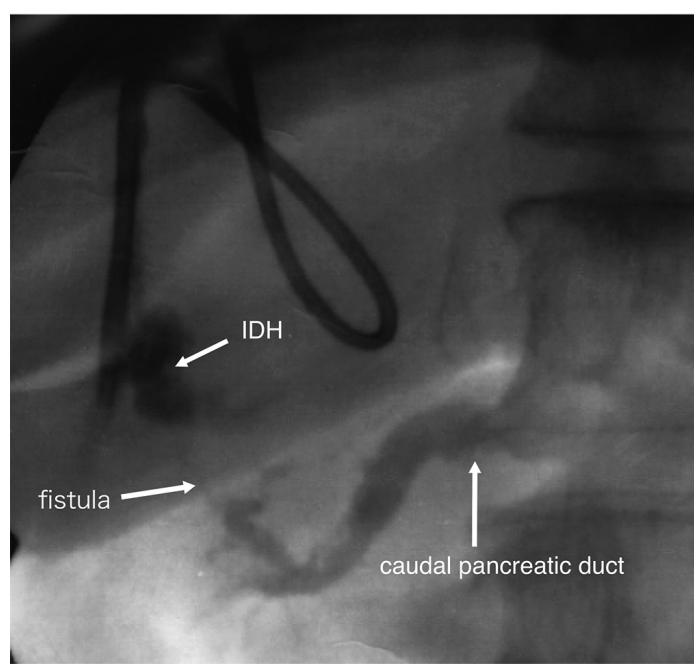

Figure 2 Contrasting from a percutaneous drainage tube in the intramural duodenal haematoma (IDH) shows the fistula from the pancreatic duct.

symptoms by 7-10 days after the start of treatment. Although our patient also was treated conservatively with fasting and infusion therapy for 2 weeks, he continued bleeding and duodenal obstruction. So we performed percutaneous drainage to reduce haematoma. Initially, drainage discharge was bloody, but turned clear on day 2. Biochemical examination of drainage discharge showed high amylase levels of more than 100000 (U/L). From percutaneous drainage tube, $100-150 \mathrm{~mL} /$ day of clear fluid continued to be discharged, so we suspected there was fistula between IDH and the pancreatic duct. Contrasting from a percutaneous drainage tube placed in IDH exhibited the caudal pancreatic duct and proved the presence of fistula (figure 2). From these results, it was found that the pancreatic fistula due to exacerbation of chronic pancreatitis contributed to the formation of IDH. Endoscopic treatment was considered the first

\section{Learning points}

Intramural duodenal haematoma (IDH) has often been described as a complication of blunt trauma to the abdomen and iatrogenic trauma, and IDH derived from acute or chronic pancreatitis is rarely described.

- A pancreatic fistula due to pancreatitis contributed to the formation of IDH in this case. 
choice, but in this case Frey procedure was performed because there was also the influence of chronic pancreatitis accompanied by many huge pancreatic stones. ${ }^{3}$ After transecting the pancreatic duct, we collected many pancreatic stones and performed pancreaticojejunal anastomosis and jejunojejunostomy for the Roux limb. Discharge of pancreatic juice from the percutaneous drainage tube decreased remarkably after surgery. On postoperative day 12, percutaneous drainage tube could be withdrawn. The mechanism of IDH associated with pancreatitis has never been reported and this case is the first.

Contributors JK is the first author and corresponding author of this manuscript. HN collected the clinical data. NY and KS revised the manuscript. All authors read and approved the final manuscript.

Funding This research received no specific grant from any funding agency in the public, commercial or not-for-profit sectors.
Competing interests None declared.

\section{Patient consent Obtained.}

Provenance and peer review Not commissioned; externally peer reviewed.

(C) BMJ Publishing Group Ltd (unless otherwise stated in the text of the article) 2018. All rights reserved. No commercial use is permitted unless otherwise expressly granted.

\section{REFERENCES}

1 Fukunaga N, Ishikawa M, Yamamura Y, et al. Spontaneous intramural duodenal hematoma complicating acute pancreatitis. Surgery 2011;149:143-4.

2 Nolan GJ, Bendinelli C, Gani J. Laparoscopic drainage of an intramural duodenal haematoma: a novel technique and review of the literature. World I Emerg Surg 2011;6:42.

3 Bachmann K, Tomkoetter L, Kutup A, et al. Is the Whipple procedure harmful for long-term outcome in treatment of chronic pancreatitis? 15-years follow-up comparing the outcome after pylorus-preserving pancreatoduodenectomy and Frey procedure in chronic pancreatitis. Ann Surg 2013;258:815-21.

Copyright 2018 BMJ Publishing Group. All rights reserved. For permission to reuse any of this content visit http://group.bmi.com/group/rights-licensing/permissions.

BMJ Case Report Fellows may re-use this article for personal use and teaching without any further permission.

Become a Fellow of BMJ Case Reports today and you can:

- Submit as many cases as you like

- Enjoy fast sympathetic peer review and rapid publication of accepted articles

- Access all the published articles

- Re-use any of the published material for personal use and teaching without further permission

For information on Institutional Fellowships contact consortiasales@bmjgroup.com

Visit casereports.bmj.com for more articles like this and to become a Fellow 